Research Paper

\title{
Incidence of menopausal symptoms in postmenopausal breast cancer patients treated with aromatase inhibitors
}

\author{
Dongsheng Hong ${ }^{1, *}$, Ling $\mathrm{Bi}^{2, *}$, Jun Zhou ${ }^{1, *}$, Yinghui Tong ${ }^{3}$, Qingwei Zhao ${ }^{1}$, Jing \\ Chen ${ }^{4}$ and Xiaoyang Lu ${ }^{1}$ \\ ${ }^{1}$ Department of Pharmacy, The First Affiliated Hospital of College of Medicine, Zhejiang University, Hangzhou, 310003, \\ P.R. China \\ ${ }^{2}$ Department of Stomatology, The First Affiliated Hospital, School of Medicine, Zhejiang University, Hangzhou, 310003, \\ P.R. China \\ ${ }^{3}$ Department of Pharmacy, Zhejiang Cancer Hospital, Hangzhou, 310022, P.R. China \\ ${ }^{4}$ Department of Medical Oncology, The First Affiliated Hospital of College of Medicine, Zhejiang University, Hangzhou, 310003, \\ P.R. China \\ *These authors have contributed equally to this work \\ Correspondence to: Jing Chen, email: angelcq@zju.edu.cn \\ Xiaoyang Lu, email: Ixy00711@126.com
}

Keywords: breast cancer, aromatase inhibitors, menopausal symptoms, hot flashes, meta-analysis

Received: January 02, $2017 \quad$ Accepted: April 02, $2017 \quad$ Published: April 18, 2017

Copyright: Hong et al. This is an open-access article distributed under the terms of the Creative Commons Attribution License 3.0 (CC BY 3.0), which permits unrestricted use, distribution, and reproduction in any medium, provided the original author and source are credited.

\section{ABSTRACT}

Aromatase inhibitors (AIs) are the standard of care for postmenopausal women with estrogen receptor-positive breast cancer. Here, we performed a metaanalysis to evaluate the occurrence of menopausal symptoms in breast cancer patients receiving the AI therapy. Patients treated with AIs had an increased risk of all-grade arthralgia (1.63 [95\% CI: 1.34-1.98]) and insomnia (1.24 [95\% CI: 1.14-1.34]). The overall incidence of hot flashes, fatigue, arthralgia, sweating, and insomnia in patients receiving AIs was 30.47\% (95\% CI: $25.51 \%-35.93 \%), 17.16 \%$ (95\% CI: 14\%-20.85\%), 17.91\% (95\% CI: 11.29\%-27.22\%), 14.64\% (95\% CI: $11.46 \%-18.52 \%)$, and $16.52 \%$ (95\% CI: $12.45 \%-21.6 \%)$, respectively. Both arthralgia ( $R R=0.34,95 \%$ CI: $0.16-0.75)$ and sweating ( $R R=11.02,95 \%$ CI: 4.1129.57) differed between patients with early- and advanced-stage breast cancer. Our findings indicates that AIs are associated with a significant risk of developing arthralgia and insomnia in breast cancer patients. Effective early detection and management of menopausal symptoms would likely lead to safer use of AIs in breast cancer patients.

\section{INTRODUCTION}

Breast cancer is one of the most common malignancies and causes of tumor-related deaths among women worldwide [1]. Most of the breast cancer patients are postmenopausal at the time of diagnosis, or reach menopause following anti-cancer treatment. Aromatase inhibitors (AIs) are a cornerstone of the standard of care for most postmenopausal breast cancer patients who are progesterone receptor and/or estrogen-receptor positive [2]. Anastrozole, letrozole, and exemestane are AIs that have been used in randomized control trials (RCTs) and demonstrated advantage compared with tamoxifen
[3-5]. Several studies have indicated that AIs may have side effects, such as genitourinary or musculoskeletal discomfort [6, 7]. However, the full impact of AIs on menopausal symptoms (MS) in breast cancer patients is not known.

MS related to breast cancer include hot flashes, fatigue, arthralgia, sweating, and insomnia; more than $50 \%$ of menopausal women report sweating and hot flashes [8-10]. MS induced by AIs have been reported in several RCTs, but the specific risk of MS associated with AIs has not been defined. Here, we conducted a systematic review and meta-analysis to evaluate the association of AI therapies with MS in breast cancer patients. 


\section{RESULTS}

\section{Search results and study characteristics}

Through initial search, 9,284 potentially relevant studies were identified. After reviewing titles and abstracts, 1,285 studies were selected for full evaluation. Ultimately, 17 studies met our inclusion criteria, and 9,054 subjects were included in our analysis [5, 11-26]. Figure 1 outlines the selection process in detail. From the selected studies, 14 RCTs were based in Europe [5, 11-23], seven in North America $[12,14,15,18,19,23,24]$, seven in the AsiaPacific region [12-15, 19, 25, 26], and one in Africa [12]. The age of subjects ranged from 35 to 96 years. Duration of follow-up times ranged from 18 to 100 months, but the majority had 30-month follow-up times. The quality of the 17 studies was high: five studies had Jadad scores of $5[13,15,17-19]$, six studies had Jadad scores of $4[5,16$, $20-22,26]$, and six studies had Jadad scores of $3[11,12,14$, 23-25]. The detailed information is shown in Tables 1 and 4, and the Supplementary Material is shown in Supplementary Table 3 .

This meta-analysis was performed in accordance with the guidelines of the Preferred Reporting Items for Systematic Reviews and Meta-Analyses (PRISMA) (Supplementary Table 2) [27].

\section{Overall incidence of MS}

Seventeen studies involving 25,062 postmenopausal women examined the association between AIs and MS [5, 11-26]. The index of MS included hot flashes, fatigue, arthralgia, sweating, and insomnia. Hot flashes were observed in 14 of the 17 studies with 7,870 events, and they ranged from 6.52 to $55.89 \%$ [11-13, 16-26]. Fatigue was observed in 11 of the 17 studies with 2,331 events, and ranged from 1.34 to $60 \%[5,11-14,16,18,21,22$, $25,26]$. Arthralgia was observed in 11 of the 17 studies with 1,672 events, and ranged from 5.25 to $54.29 \%$ [11-14, 17-19, 21, 24-26]. Sweating was observed in 4 of the 17 studies with 1,209 events, and ranged from 1.53 to $18.45 \%[18,19,21,23]$. Insomnia was observed in 5 of the 17 studies with 1,640 events, and ranged from 3.36 to $31.12 \%$ [13-15, 18, 21].

The overall incidence of hot flashes, fatigue, arthralgia, sweating, and insomnia was 30.47\% (95\% CI: $25.51 \%-35.93 \%$, Table 2 and Supplementary Figure 1$), \quad 17.16 \% \quad(95 \% \quad$ CI: $\quad 14 \%-20.85 \%$, Table 2 and Supplementary Figure 2), 17.91\% (95\% CI: $11.29 \%-27.22 \%$, Table 2 and Supplementary Figure 3), $14.64 \%$ (95\% CI: $11.46 \%-18.52 \%$, Table 2 and Supplementary Figure 4), and $16.52 \%$ (95\% CI: $12.45 \%-21.6 \%$, Table 2 and Supplementary Figure 5), respectively, according to the random effects model.
High-grade (grades 3 to 5) MS may result in discontinuation of AI treatment and increased morbidity. There were eight studies involving 12,885 patients with high-grade MS [12-15, 18, 19, 21, 26]. The incidence of high-grade hot flashes, fatigue, arthralgia, sweating, and insomnia was $4.14 \%$ (95\% CI: $3.61 \%-4.75 \%$, Figure 2 ), $1.25 \%$ (95\% CI: $0.98 \%-1.59 \%$, Figure 2$), 1.55 \%$ (95\% CI: $1.01 \%-2.35 \%$, Figure 2), $2.26 \%$ (95\% CI: $1.87 \%-2.73 \%$, Figure 2), and $1.19 \%$ (95\% CI: $0.71 \%-1.99 \%$, Figure 2$)$, respectively, according to the random-effects or fixedeffects models.

\section{Relative risk of all-gade MS}

We calculated the odds ratio (OR) of MS between AIs and control groups $[5,13,15-22,26]$. The pooled ORs of hot flashes, fatigue, arthralgia, sweating, and insomnia were 0.907 (95\% CI: $0.809-1.018, P$-value:0.0966, Table 3 and Supplementary Figure 6), 1.03 (95\% CI: $0.97-1.11, P$-value: 0.2552 , Table 3 and Supplementary Figure 7), 1.63 (95\% CI: $1.34-1.98, P$-value: $<0.0001$, Figure 3), 0.96 (95\% CI: 0.81-1.14, $P$-value:0.4284, Table 3 and Supplementary Figure 8), and 1.24 (95\% CI: 1.14-1.37, $P$-value:0.0966, Figure 3), respectively, according to random-effects or fixed-effects models.

We also calculated the OR of MS between AIs and tamoxifen groups $[5,15-22,26]$. The pooled ORs of hot flashes, fatigue, arthralgia, sweating, and insomnia were 0.898 (95\% CI: $0.797-1.013, P$-value:0.0797, Supplementary Figure 9), 1.04 (95\% CI: 0.97-1.11, $P$-value:0.2449, Supplementary Figure 9), 1.71 (95\% CI: $1.55-1.88, P$-value: $<0.0001$, Supplementary Figure 9), 0.96 (95\% CI: $0.82-1.14, P$-value:0.6545, Supplementary Figure 9), and 1.24 (95\% CI: 1.14-1.34, $P$-value: < 0.0001, Supplementary Figure 9), respectively, according to random-effects or fixed-effects models.

\section{Relative risk of high-grade MS}

High-grade MS is an important clinical indicator of AI safety. We analyzed the OR for high-grade MS in AIs and control groups in six RCTs that involved 25,128 patients $[13,15,18,19,21,26]$. The main MS included hot flashes, fatigue, arthralgia, sweating, and insomnia. The pooled ORs of hot flashes, fatigue, arthralgia, sweating, and insomnia were 1.14 (95\% CI: 0.93-1.41, $P$-value: 0.2124 , Figure 4), 0.92 (95\% CI: $0.65-1.29$, $P$-value: 0.6245 , Figure 4), 1.43 (95\% CI: $0.77-2.68$, $P$-value: 0.2605 , Figure 4), 0.95 (95\% CI: $0.73-1.25$, $P$-value: 0.7234 , Figure 4), and 1.26 (95\% CI: $0.95-1.65$, $P$-value: 0.1347 , Figure 4$)$, respectively, according to random-effects or fixed-effects models.

The analysis was also performed on high-grade MS between AIs and tamoxifen groups [15, 18, 19, 21, 26]. 
Table 1: Characteristics of the 17 randomized clinical trials included in our study

\begin{tabular}{lll}
\hline & Aromatase Inhibitors & Tamoxifen/Placebo \\
\hline Eligible studies & & \\
No.unique studies & 17 & 11 \\
Duration of follow-up, median (IQR), months & $36.95(30.23-54.53)$ & $37.9(30.6-55.7)$ \\
Patients & & \\
Total & 25062 & 20539 \\
Median (IQR), No. & $445(230-2770)$ & $2338(349-3093)$ \\
Age, median (IQR), years & $64(62.5-64.2)$ & $63.2(60.9-64)$ \\
Location & & \\
Europe & 14 & 10 \\
North America & 7 & 3 \\
Asia-Pacific & 7 & 4 \\
Africa & 1 & 0 \\
\hline
\end{tabular}

Abbreviation: IQR, interquartile range.

Table 2: Incidence of menopausal symptoms in postmenopausal breast cancer patients assigned to aromatase inhibitor intervention

\begin{tabular}{lcccc}
\hline $\begin{array}{l}\text { Menopausal } \\
\text { Symptoms }\end{array}$ & $\begin{array}{c}\text { Number of Included } \\
\text { Studies }\end{array}$ & $\begin{array}{c}\text { Number of Menopausal } \\
\text { Symptoms }\end{array}$ & Number of Patients & Incidence (95\% CI) \\
\hline Hot flashes & 14 & 7870 & 19749 & $30.47 \%(25.51 \%-35.93 \%)$ \\
Fatigue & 11 & 2331 & 12175 & $17.16 \%(14 \%-20.85 \%)$ \\
Arthralgia & 11 & 1672 & 12421 & $17.91 \%(11.29 \%-27.22 \%)$ \\
Sweating & 4 & 1209 & 7392 & $14.64 \%(11.46 \%-18.52 \%)$ \\
Insomnia & 5 & 1640 & 10013 & $16.52 \%(12.45 \%-21.60 \%)$ \\
\hline
\end{tabular}

Table 3: Meta-analysis of other menopausal symptoms in postmenopausal breast cancer patients assigned to aromatase inhibitor or control intervention

\begin{tabular}{|c|c|c|c|c|c|c|}
\hline \multirow{2}{*}{$\begin{array}{l}\text { Menopausal } \\
\text { Symptoms }\end{array}$} & \multirow{2}{*}{$\begin{array}{c}\text { Number of Included } \\
\text { Studies }\end{array}$} & \multicolumn{2}{|c|}{ Number of Menopausal Symptoms } & \multirow{2}{*}{ OR $(95 \% C I)$} & \multirow{2}{*}{$P$-value } & \multirow{2}{*}{ Heterogeneity,Q; P; I } \\
\hline & & Aromatase inhibitor & Control & & & \\
\hline Hot flashes & 9 & $5691 / 15467$ & $6075 / 15500$ & $0.9071(0.8086-1.0177)$ & 0.0966 & $0.0211 ;<0.0001 ; 79.8 \%$ \\
\hline Fatigue & 6 & $2260 / 11454$ & $2201 / 11484$ & $1.0389(0.9728-1.1094)$ & 0.2552 & $0 ; 0.9753 ; 0 \%$ \\
\hline Sweating & 4 & $1205 / 7130$ & $1247 / 7165$ & $0.9626(0.8146-1.1375)$ & 0.4284 & $0.0158 ; 0.0254 ; 72.8 \%$ \\
\hline
\end{tabular}

$\mathrm{OR}=$ odds ratio.

The main MS included hot flashes, fatigue, arthralgia, sweating, and insomnia. The pooled ORs of hot flashes, fatigue, arthralgia, sweating, and insomnia were 1.14 (95\% CI: 0.93-1.41, $P$-value: 0.2124, Supplementary Figure 10), 0.93 (95\% CI: 0.66-1.32, $P$-value: 0.6936, Supplementary Figure 10), 1.74 (95\% CI: 1.19-2.53, $P$-value: 0.0042 , Supplementary Figure 10), 0.95 (95\% CI: $0.73-1.25$, $P$-value: 0.7234, Supplementary Figure 10), and 1.32 (95\% CI: 1.00-1.75, $P$-value: 0.0535 ,
Supplementary Figure 10), respectively, according to random-effects or fixed-effects models.

Incidence of MS in patients with advanced-stage vs. early-stage breast cancer

To determine whether the incidence of MS was associated with breast cancer stage, we analyzed the occurrence of MS in advanced-stage and early-stage breast 
Table 4: Baseline characteristics of randomized clinical trials included in the meta-analysis

\begin{tabular}{|c|c|c|c|c|c|c|c|c|c|c|c|c|c|}
\hline \multirow{2}{*}{$\begin{array}{c}\text { Author } \\
\text { (Publication Date) }\end{array}$} & \multirow{2}{*}{ Trial phase } & \multirow{2}{*}{ Tumor staging } & \multirow{2}{*}{ Interventions } & \multirow{2}{*}{ Age (range, years) } & \multirow{2}{*}{$\begin{array}{c}\text { follow-up } \\
\text { (media,months) }\end{array}$} & \multicolumn{5}{|c|}{ Events of Menopausal Symptoms } & \multirow{2}{*}{$\begin{array}{l}\text { No. of } \\
\text { Patiens }\end{array}$} & \multirow{2}{*}{$\begin{array}{l}\text { Jadad } \\
\text { score }\end{array}$} & \multirow{2}{*}{$\begin{array}{l}\text { References } \\
\text { Number }\end{array}$} \\
\hline & & & & & & Hot Flashes & Fatigue & Arthralgia & Sweating & Insomnia & & & \\
\hline Tryfonidis (2016) & Phase 2 Trial & Advanced-stage breast cancer & Anastrozole (1 mg/d) & $63.9(42.8-84.4)$ & 18 & 13 & 21 & 19 & NR & NR & 35 & 3 & 11 \\
\hline Richard (2015) & Phase 3 trial & Advanced-stage breast cancer & Letrozole $2.5 \mathrm{mg} / \mathrm{d}$ & $64(56-70)$ & 29.6 & 9 & 18 & 12 & NR & NR & 77 & 3 & 12 \\
\hline \multirow[t]{2}{*}{ Stephen (2013) } & \multirow[t]{2}{*}{ Phase 3 trial } & \multirow[t]{2}{*}{ Advanced-stage breast cancer } & Fulvestrant plus anastrozole & $63.8(57-72)$ & 37.9 & 88 & 7 & 97 & $\mathrm{NR}$ & 75 & 241 & \multirow[t]{2}{*}{5} & \multirow[t]{2}{*}{13} \\
\hline & & & Fulvestrant plus placebo & $63.4(57-73.5)$ & NR & 81 & 8 & 98 & NR & 63 & 230 & & \\
\hline Hiroji (2013) & Phase 3 trial & Advanced-stage breast cancer & Anastrozole (1 mg/d) & $164(9) *$ & 60.1 & 22 & 2 & 25 & $\mathrm{NR}$ & NR & 149 & 3 & 25 \\
\hline Paul (2013) & Phase 3 trial & Early-stage breast cancer & Anastrozole & 64.3 & 49.2 & 2101 & NR & 231 & NR & NR & 3759 & 3 & 24 \\
\hline Baselga (2012) & Phase 3 trial & Advanced-stage breast cancer & Exemestane & 62 & NR & NR & 26 & 16 & $\mathrm{NR}$ & 8 & 238 & 3 & 14 \\
\hline \multirow{2}{*}{ Velde (2011) } & \multirow{2}{*}{ Phase 3 trial } & \multirow{2}{*}{ Early-stage breast cancer } & Exemestane ( $25 \mathrm{mg} / \mathrm{d})$ & $64(35-96)$ & 61.2 & NR & NR & NR & $\mathrm{NR}$ & 654 & 4852 & \multirow[t]{2}{*}{5} & \multirow[t]{2}{*}{15} \\
\hline & & & exemestane following tamoxifen & NR & NR & NR & NR & NR & NR & 504 & 4814 & & \\
\hline \multirow[t]{2}{*}{ Tomohiko (2010) } & \multirow[t]{2}{*}{ Phase 3 trial } & \multirow[t]{2}{*}{ I, IIA, IIB/IIIA/IIIB } & Anastrozole ( $1 \mathrm{mg} / \mathrm{d}$ ) & $59.5(7.4)^{*}$ & 42 & 126 & 92 & 175 & NR & NR & 347 & \multirow[t]{2}{*}{4} & \multirow[t]{2}{*}{26} \\
\hline & & & Tamoxifen (20 mg/d) & $60.2(7.4)^{*}$ & NR & 156 & 89 & 111 & NR & NR & 349 & & \\
\hline \multirow[t]{2}{*}{ Arimidex (2008) } & \multirow{2}{*}{ Phase 3 trial } & Early-stage breast cancer & Anastrozole (1 mg/d) & $64(9)^{*}$ & 100 & 1102 & 578 & NR & NR & NR & 3092 & 4 & 16 \\
\hline & & & Tamoxifen $(20 \mathrm{mg} / \mathrm{d}$ ) & NR & NR & 1263 & 544 & NR & NR & NR & 3094 & & \\
\hline Kaufinaann (2007) & Phase 3 trial & Early-stage breast cancer & Anastrozole (1 mg/d) & 60.9 & 30.1 & 29 & NR & 52 & NR & NR & 445 & 5 & 17 \\
\hline & & & Tamoxifen $(20-30 \mathrm{mg} / \mathrm{d}$ ) & 60.5 & NR & 29 & NR & 22 & NR & NR & 452 & & \\
\hline Coombes (2007) & Phase 3 trial & Early-stage breast cancer & Exemestane ( 25 mg/d) & NR & 55.7 & 957 & 526 & 432 & 428 & 454 & 2320 & 5 & 18 \\
\hline & & & Tamoxifen $(20-30 \mathrm{mg} / \mathrm{d}$ ) & NR & NR & 903 & 522 & 275 & 413 & 393 & 2338 & & \\
\hline Coates (2007) & Phase 3 trial & Early-stage breast cancer & letrozole $2.5 \mathrm{mg} / \mathrm{d}$ & NR & 51 & 803 & NR & 489 & 348 & NR & 2448 & 5 & 19 \\
\hline & & & Tamoxifen (20 mg/d) & NR & NR & 914 & NR & 331 & 416 & NR & 2447 & & \\
\hline Jakesz (2005) & Phase 3 trial & Early-stage breast cancer & Anastrozole ( $1 \mathrm{mg} / \mathrm{d}$ ) & $62 \cdot 3(46 \cdot 0-80 \cdot 3)$ & 28 & 537 & NR & NR & $\mathrm{NR}$ & NR & 1120 & 4 & 20 \\
\hline & & & Tamoxifen (20-30 mg/d) & $62 \cdot 0(41 \cdot 4-80 \cdot 0)$ & NR & 560 & NR & NR & NR & NR & 1117 & & \\
\hline Boccardo (2005) & Phase 3 trial & Early-stage breast cancer & Anastrozole (1 mg/d) & $63(38-76)$ & 36 & NR & 4 & NR & $\mathrm{NR}$ & NR & 223 & 4 & 5 \\
\hline & & & Tamoxifen (20 mg/d) & $63(43-77)$ & NR & NR & 0 & NR & NR & NR & 225 & & \\
\hline Coombes (2004) & Phase 3 trial & Early-stagc breast cancer & Exemestane $(25 \mathrm{mg} / \mathrm{d})$ & $64.3(8.1)^{*}$ & 30.6 & 967 & 545 & 124 & 429 & 449 & 2362 & 4 & 21 \\
\hline & & & Tamoxifen $(20 \mathrm{mg} / \mathrm{d})$ & $64.2(8.2)^{*}$ & NR & 923 & 547 & 85 & 418 & 406 & 2380 & & \\
\hline Baum (2003) & Phase 3 trial & Early-stage breast cancer & Anastrozole ( $1 \mathrm{mg} / \mathrm{d}$ ) & NR & 33 & 1082 & 512 & NR & $\mathrm{NR}$ & NR & 3092 & 4 & 22 \\
\hline & & & Tamoxifen $(20 \mathrm{mg} / \mathbf{d}$ ) & NR & $\mathrm{NR}$ & 1246 & 491 & NR & $\mathrm{NR}$ & NR & 3093 & & \\
\hline Buzdar (1998) & Phase 3 trial & Advanced-stage breast cancer & Anastrozole $(1 \mathrm{mg} / \mathrm{d})$ & $65.6(10.9)^{*}$ & 31 & 34 & $\mathrm{NR}$ & NR & 4 & NR & 262 & 3 & 23 \\
\hline
\end{tabular}

々, date as show with mean(SD); number(percentage); No. of Patients, Number of enrolled patients; NR, Not Reported;

cancer patients. To calculate the relative risk (RR), we used the comparison of two estimated quantities [28]. The all-grade incidence of arthralgia was significantly decreased in patients with early-stage breast cancer compared with advanced-stage breast cancer $(\mathrm{RR}=0.34,95 \% \mathrm{CI}$ : $0.16-0.75)$, but the all- grade incidence of sweating was significantly increased $(\mathrm{RR}=11.02,95 \% \mathrm{CI}: 4.11-29.57)$. No difference was detected in the all-grade incidence of hot flashes $(\mathrm{RR}=1.72$, 95\% CI: 0.95-3.09), fatigue (RR = 1.52, 95\% CI: 0.30-7.59), and insomnia $(\mathrm{RR}=1.51,95 \% \mathrm{CI}: 0.19-11.83)$.

\section{4 studies identified \\ through database searching}

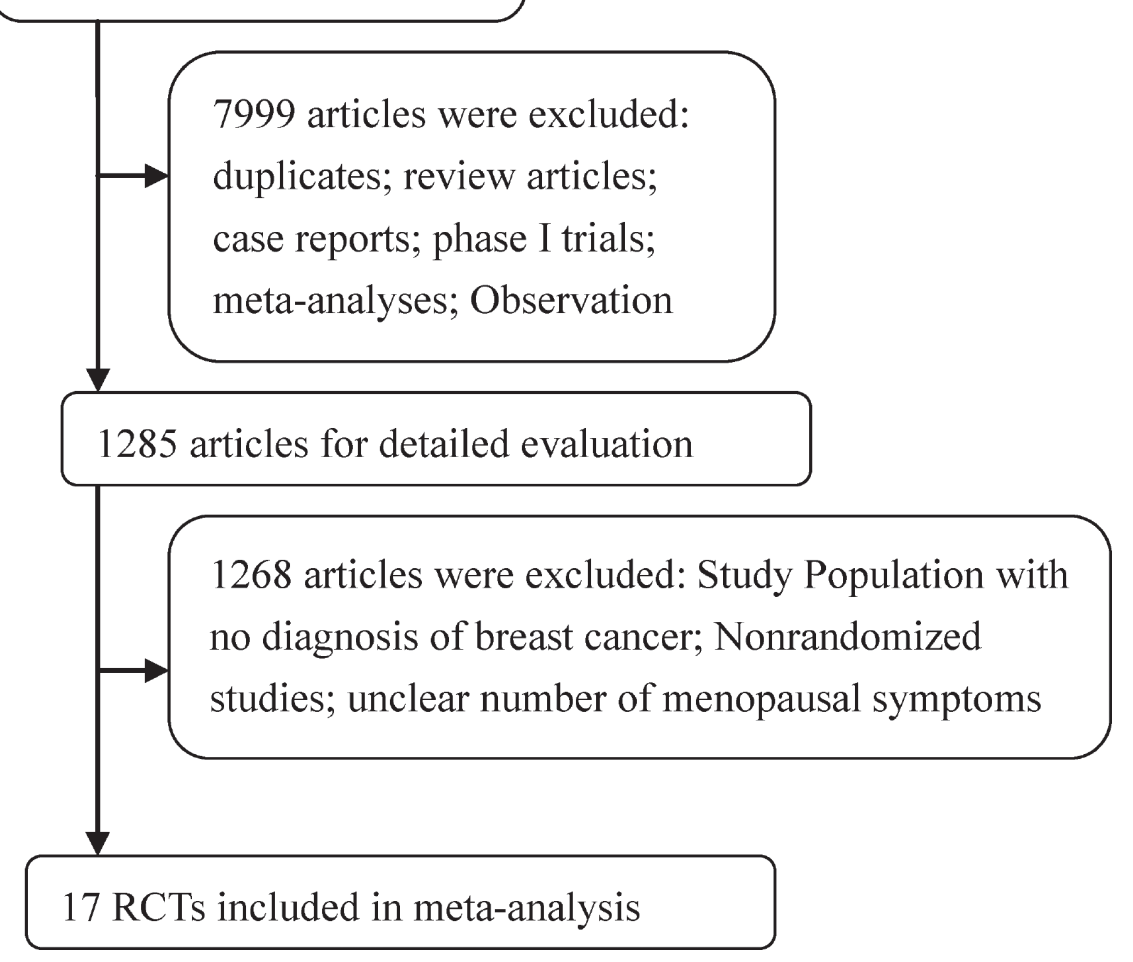

Figure 1: Flow chart demonstrating process of study selection. 
No statistical difference was found in the highincidence of fatigue $(\mathrm{RR}=2.16$ [95\% CI 0.69-6.80]), arthralgia $(\mathrm{RR}=0.78$ [95\% CI: 0.26-2.38]), and insomnia $(\mathrm{RR}=3.10$ [95\% CI 0.42-23.04]) between patients with advanced-stage and early-stage cancers.

\section{Publication bias}

No evidence of publication bias was found for the OR of MS of hot flashes in our meta-analysis by funnel plots (Figure 5), Egger's test $(P=0.891>0.05,95 \% \mathrm{CI}$ : $-2.81,3.17)$, or Begg's test $(Z=0.12<1.96, P=0.903$
$>0.05)$. Heterogeneity of different rates of occurrence in the various clinical trials was statistically significant, and data of MS were analyzed using a random-effects model.

\section{DISCUSSION}

Our study indicates that the use of AIs in breast cancer patients is associated with an increased risk of menopausal symptoms (MS). Patients on AI therapy had a high overall incidence of all-grade MS, including hot flashes $(30.47 \%)$, fatigue (17.16\%), arthralgia (17.91\%), sweating (14.64\%), and insomnia (16.52\%). They also

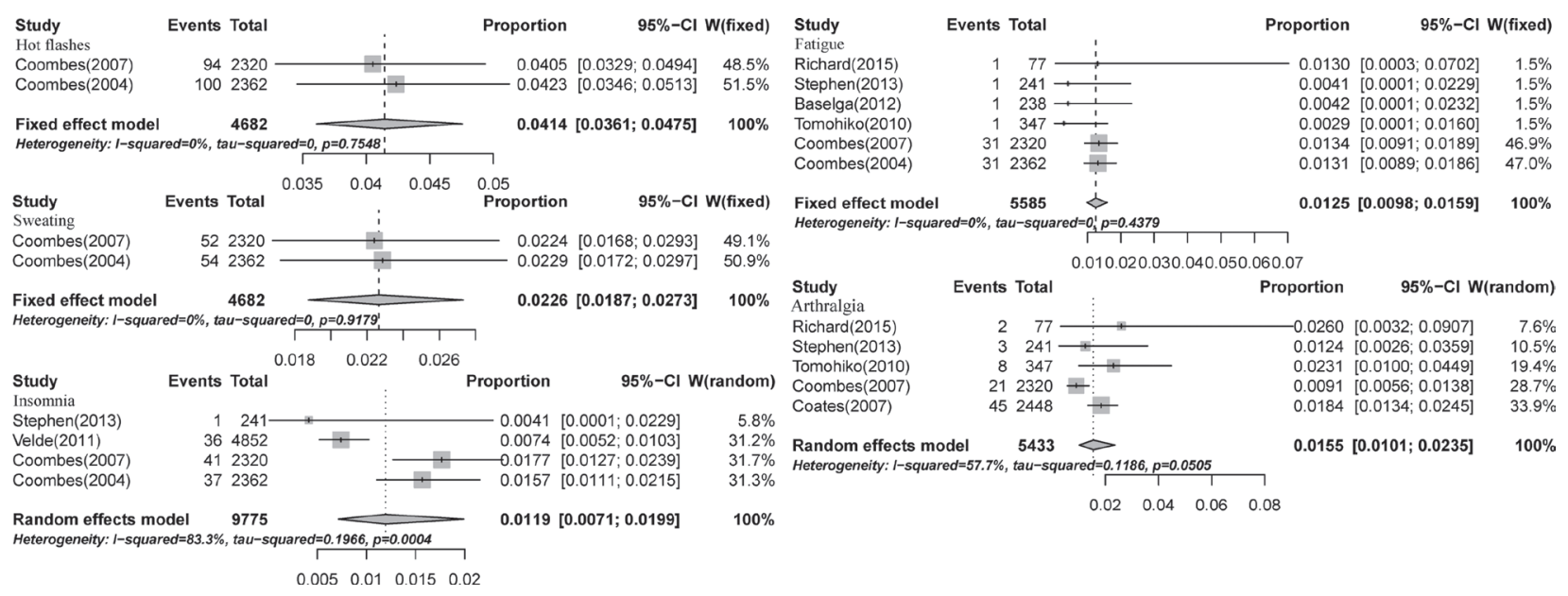

Figure 2: Forest plot for meta-analysis of incidence of all-grade menopausal symptoms in postmenopausal breast cancer patients receiving aromatase inhibitors.

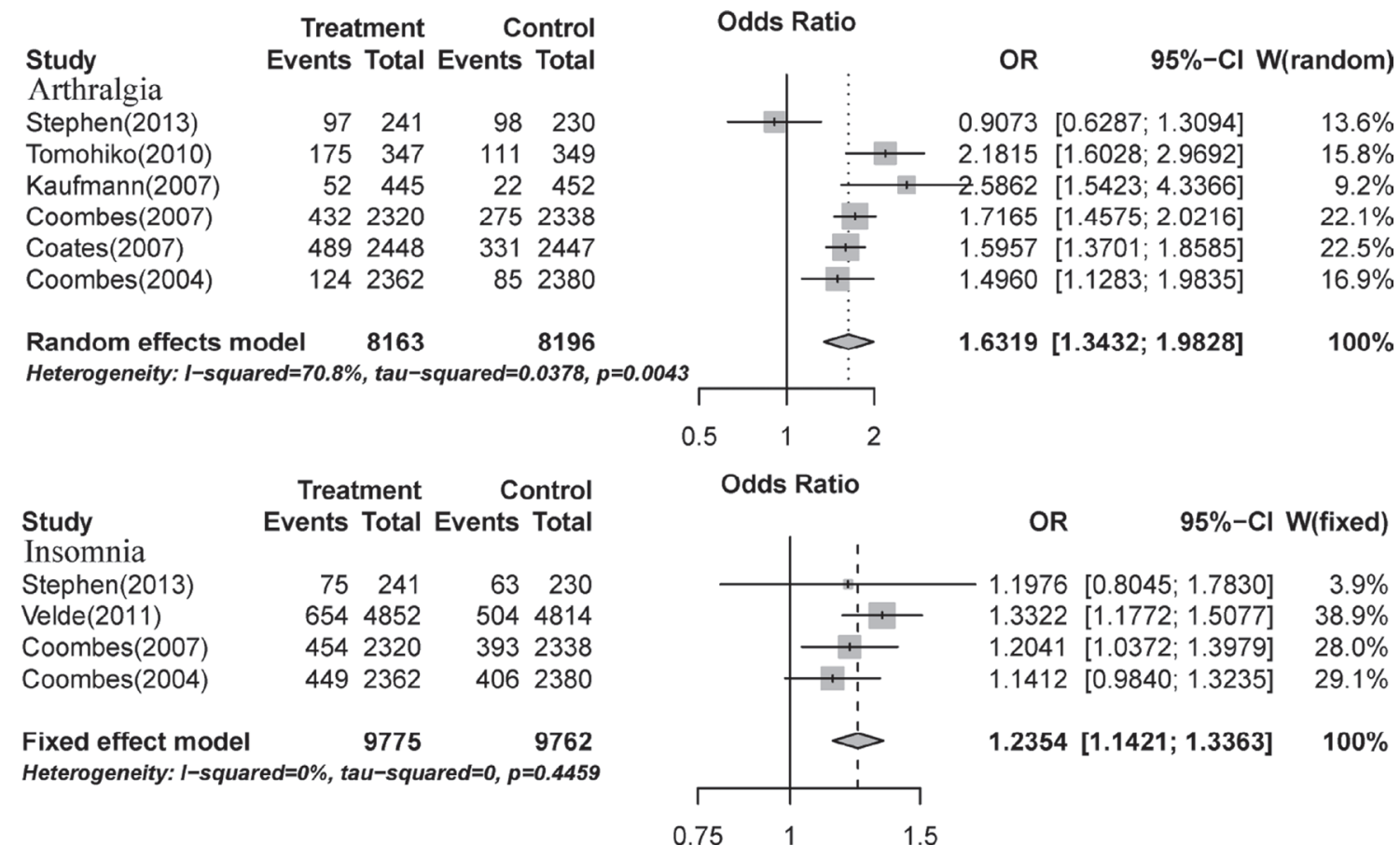

Figure 3: Relative risk of aromatase-inhibitor-associated all-grade arthralgia and insomnia vs. control from included studies with postmenopausal breast cancer. 
had a high overall incidence of high-grade MS, including hot flashes $(4.14 \%)$, fatigue $(1.25 \%)$, arthralgia $(1.55 \%)$, sweating (2.26\%), and insomnia (1.19\%). Aggressive and adequate management of moderate MS is important for cancer patients, because the negative effect of endocrine therapy on quality of life is a major concern [29, 30].

Our data are consistent with previous studies demonstrating the prevalence of vasomotor symptoms,
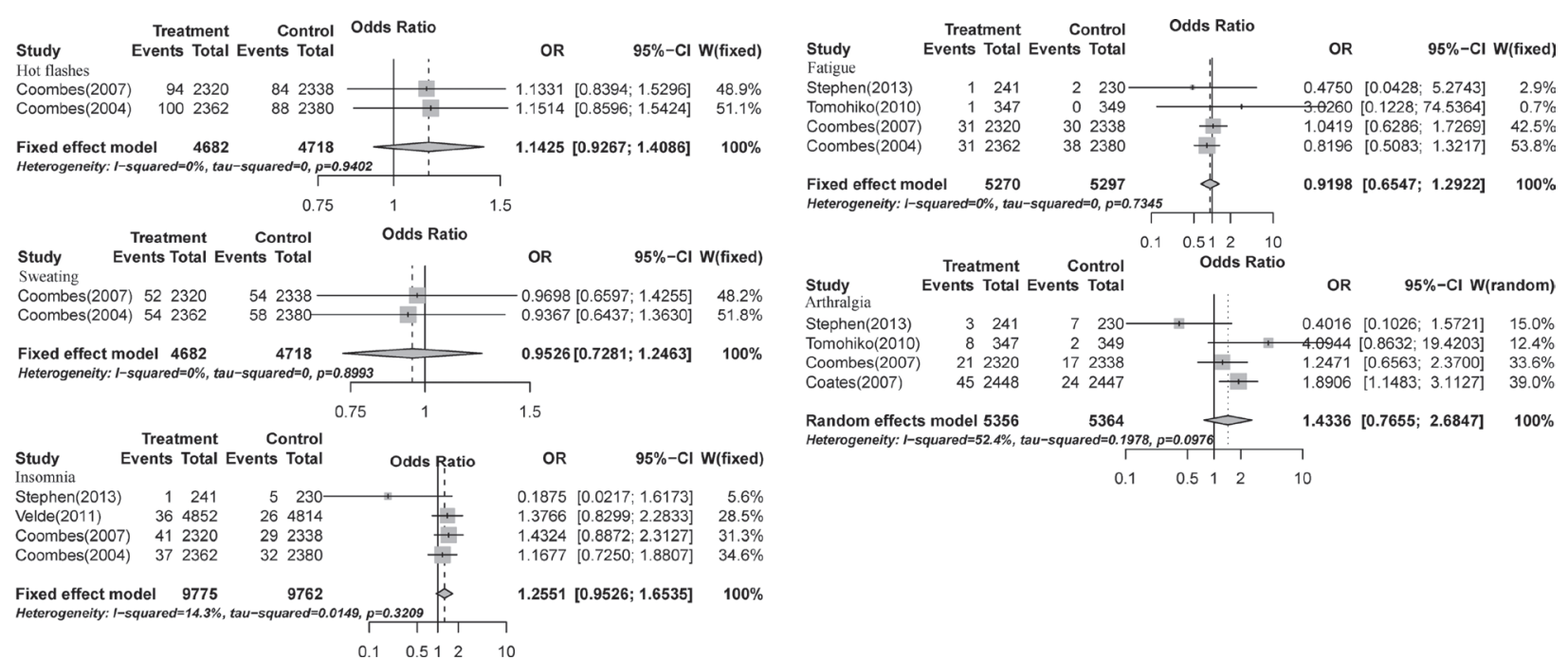

Figure 4: Relative risks of aromatase-inhibitor-associated high-grade menopausal symptoms vs. control from included studies with postmenopausal breast cancer.

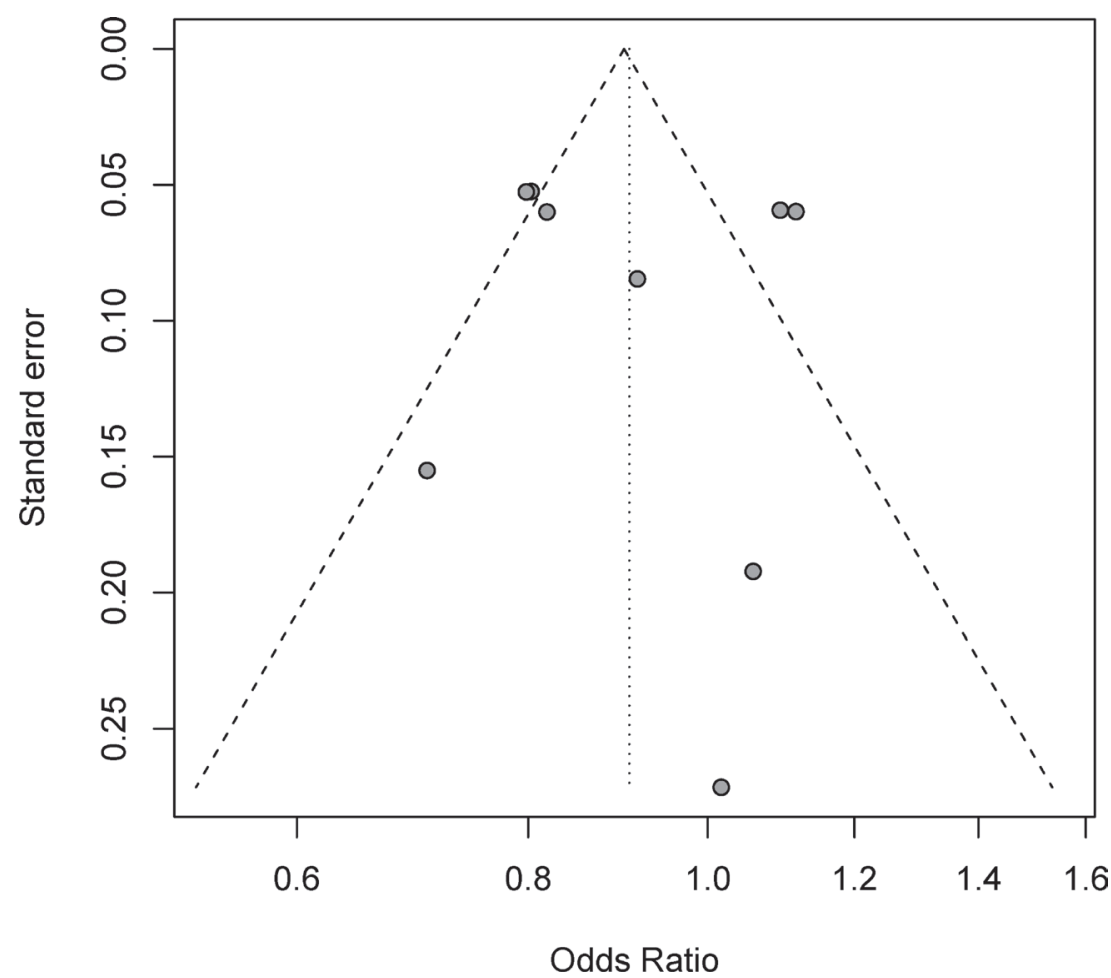

Figure 5: Funnel plots of studies reporting risk ratio for all-grade hot flashes in postmenopausal breast cancer patients receiving aromatase inhibitors and control. such as sweating and hot flashes, and fatigue, arthralgia, and insomnia in breast cancer patients [29, 31]. In addition, we have found that the AI therapy is associated with an increased incidence of all-grade arthralgia and insomnia, but not with hot flashes, fatigue, or sweating. The ORs of high-grade incidences of hot flashes, fatigue, arthralgia, sweating, and insomnia were 1.14, 0.92, 1.43, 0.95 , and 1.26, respectively. Because of the increased risk 
of arthralgia and insomnia, it is necessary for physicians and oncologists to be aware of the increased risk of MS associated with AIs and treat them appropriately.

The risk of MS may vary depending on the tumor stage. Indeed, our results indicate that the incidence of arthralgia in early-stage breast cancer patients is lower than in advanced-stage breast cancer patients, whereas the incidence of sweating in early stages is higher than in other stages. The different occurrence of arthralgia and sweating in different tumor-stages may be due to the development of the disease itself and/or medications. The patients need to know that there are different MS depending on the disease stages.

The MS during natural or medically induced menopause are associated with the rapid decline of estrogen levels $[32,33]$. Premenopausal and reproductiveage women usually do not suffer from these symptoms [34]. In contrast, breast cancer patients often suffer from MS because of endocrine therapy or chemotherapy [35-37]. Therefore, having MS following therapy for a breast tumor may indicate decreased circulating estrogen levels and favorable prognosis [38, 39]. This hypothesis is supported by our data indicating that breast cancer patients in the AI group have increased occurrence of MS compared to patients in the control group.

The management of AI-associated MS is still controversial and difficult. The role of AIs in MS symptoms may vary with the patient's age. The MS risk of women who just crossed the menopause may be higher compared to older patients. Bone-density screening should be performed in all postmenopausal breast cancer patients, since AIs can accelerate bone loss [40]. In general, hormone replacement therapy (HRT) should be avoided after an early diagnosis of breast cancer, since clinical trials have reported that it increases the risk of breast cancer recurrence [41, 42]. Since AI therapy induces MS in breast cancer patients, it may be difficult for them to distinguish whether their symptoms are induced by the drug treatment or by the disease itself. To distinguish between these two possibilities, it is sometimes necessary to suspend the drug treatment for two or more weeks. Once the majority of MS disappear, then reassessing the case or trying a different drug may be necessary [40]. Our finding is that high-grade MS of hot flashes, fatigue, arthralgia, sweating, and insomnia are not significantly different in patients receiving the AI therapy compared to other therapies, but the risk of all-grade arthralgia and insomnia is significantly increased in patients with AI treatment.

As with any meta-analysis, this study has some limitations. First, the included studies were performed at various international institutions by different researchers, and there may be a bias in the reporting of adverse events. Different methods of symptoms and risk observation were recorded in different studies. In particular, the incidence rate of MS is understated or missing in some clinical trials.
Second, the patients' baseline MS were not reported in the studies, which might have led to an overestimation of the risk of AI-associated MS. Third, there might have been potentially important differences among the studies, including different tumor types, AI dosages and administration schedules, periods of study, and study investigators. In addition, three different AIs have been used in the included studies; while exemestane is a steroidal AI, anastrozole and letrozole are non-steroidal AIs. All these factors increase the clinical heterogeneity among the included trials, making the interpretation of a meta-analysis challenging. Additionally, since RCTs have strict inclusion and exclusion criteria, the results of this meta-analysis may not represent those found in patients [43, 44].

Together, our study shows that AIs are associated with a significant risk of developing all-grade MS of arthralgia and insomnia, and that the risk of arthralgia and sweating depends on the tumor stage. Effective early detection and management of MS should lead to safer use of AIs in breast cancer patients.

\section{MATERIALS AND METHODS}

\section{Search strategy and study selection}

This study was performed according to the Preferred Reporting Items for Systematic Reviews and Meta-Analyses (PRISMA) guidelines. The databases of EMBASE, PubMed, and the Cochrane Library were searched through August 3, 2016, with English language restriction. The computer search terms included the following free text and MeSH terms: "breast neoplasms," "breast cancer," "breast tumor," "mammary cancer," "aromatase inhibitors," "anastrozole," "letrozole," and "clinical trial." The details of the search strategy are summarized in Supplementary Table 1. Two independent investigators selected the eligible studies according to the selection criteria, and discrepancies were resolved by consensus. Studies were suitable if they met the following criteria: (1) Randomized clinical trials (RCTs) in postmenopausal patients with breast cancer. (2) Patients treated with aromatase inhibitors, including anastrozole, letrozole, or exemestane. (3) Data regarding end points for MS, including hot flashes, fatigue, arthralgia, sweating, and insomnia $[45,46]$. These clinical end points were obtained according to the Common Terminology Criteria for Adverse Events (CTCAE) of the National Cancer Institute (https://ctep.cancer.gov/protocoldevelopment/electronic applications/ctc.htm\#ctc_archive).

\section{Data extraction and quality assessment}

Index of the MS included hot flashes, fatigue, arthralgia, sweating, and insomnia. Data were extracted from the safety profile of each RCT. Two independent investigators extracted data that included patient 
characteristics, regional distribution, treatment measures, follow-up time, and outcome data. Quality assessment was performed by the methodologies of Jadad criteria [47], and studies with scores of $\geq 3$ were classified as high quality.

\section{Data analysis}

The principal summary measures were incidence, odds ratio (OR), and corresponding 95\% CI. To calculate incidence, the number of patients with MS and the number of patients receiving aromatase inhibitors were extracted. The proportion of patients with MS and 95\% CI were calculated in each study. The OR of MS was calculated only with those assigned to the control group in the same trial. A statistical test with a $P$ value less than 0.05 was considered significant. We used the Peto method to calculate the OR and $95 \%$ CI because this method provides the best confidence interval coverage, and it is more powerful and less biased when calculating low event rates [48]. Heterogeneity among clinical trials was assessed using the Q statistic and I2 tests.[49, 50] To calculate the pooled incidence, an inverse variance statistical method was used. Heterogeneity was considered statistically significant when $P<0.1$ or I $>40 \%$. If heterogeneity existed, the data were analyzed using a random-effects model; if heterogeneity did not exist, a fixed-effects model was used. The presence of publication bias was evaluated using the funnel plot, Begg's test, and Egger's test [51, 52]. All data analyses were performed using R software version 3.0.3 ( $\mathrm{R}$ foundation for statistical computing, http://www.r-project.org).

\section{CONFLICTS OF INTEREST}

The authors have declared no conflicts of interest.

\section{REFERENCES}

1. Jemal A, Siegel R, Ward E, Hao Y, Xu J, Thun MJ. Cancer statistics, 2009. CA Cancer J Clin. 2009; 59:225-49. doi: 10.3322/caac. 20006

2. Burstein HJ, Prestrud AA, Seidenfeld J, Anderson H, Buchholz TA, Davidson NE, Gelmon KE, Giordano SH, Hudis CA, Malin J, Mamounas EP, Rowden D, Solky AJ, et al. American Society of Clinical Oncology clinical practice guideline: update on adjuvant endocrine therapy for women with hormone receptor-positive breast cancer. J Clin Oncol. 2010; 28:3784-96. doi: 10.1200/JCO.2009.26.3756.

3. Boccardo F, Guglielmini $\mathrm{P}$, Bordonaro R, Fini A, Massidda B, Porpiglia M, Roagna R, Serra P, Orzalesi L, Ucci G, Rubagotti A. Switching to anastrozole versus continued tamoxifen treatment of early breast cancer: long term results of the Italian Tamoxifen Anastrozole trial. Eur J Cancer. 2013; 49:1546-54. doi: 10.1016/j.ejca.2012.12.025.
4. Boccardo F, Rubagotti A, Guglielmini P, Fini A, Paladini G, Mesiti M, Rinaldini M, Scali S, Porpiglia M, Benedetto C, Restuccia N, Buzzi F, Franchi R, et al. Switching to anastrozole versus continued tamoxifen treatment of early breast cancer. Updated results of the Italian tamoxifen anastrozole (ITA) trial. Ann Oncol. 2006; 17:vii10-4. doi: 10.1093/annonc/md1941.

5. Boccardo F, Rubagotti A, Puntoni M, Guglielmini P, Amoroso D, Fini A, Paladini G, Mesiti M, Romeo D, Rinaldini M, Scali S, Porpiglia M, Benedetto C, et al. Switching to anastrozole versus continued tamoxifen treatment of early breast cancer: preliminary results of the Italian Tamoxifen Anastrozole Trial. J Clin Oncol. 2005; 23: 5138-47. doi: 10.1200/jco.2005.04.120.

6. Josefsson ML, Leinster SJ. Aromatase inhibitors versus tamoxifen as adjuvant hormonal therapy for oestrogen sensitive early breast cancer in post-menopausal women: meta-analyses of monotherapy, sequenced therapy and extended therapy. Breast. 2010; 19:76-83. doi: 10.1016/j. breast.2009.12.010.

7. Amir E, Seruga B, Niraula S, Carlsson L, Ocana A. Toxicity of adjuvant endocrine therapy in postmenopausal breast cancer patients: a systematic review and meta-analysis. J Natl Cancer Inst. 2011; 103:1299-309. doi: 10.1093/jnci/djr242.

8. Hasper I, Ventskovskiy BM, Rettenberger R, Heger PW, Riley DS, Kaszkin-Bettag M. Long-term efficacy and safety of the special extract ERr 731 of Rheum rhaponticum in perimenopausal women with menopausal symptoms. Menopause. 2009; 16:117-31. doi: 10.1097/ GME.0b013e3181806446.

9. Dibonaventura MD, Chandran A, Hsu MA, Bushmakin A. Burden of vasomotor symptoms in France, Germany, Italy, Spain, and the United Kingdom. Int J Womens Health. 2013; 5:261-9. doi: 10.2147/IJWH.S39027.

10. Reed SD, Lampe JW, Qu C, Gundersen G, Fuller S, Copeland WK, Newton KM. Self-reported menopausal symptoms in a racially diverse population and soy food consumption. Maturitas. 2013; 75:152-8. doi: 10.1016/j. maturitas.2013.03.003.

11. Tryfonidis K, Basaran G, Bogaerts J, Debled M, Dirix L, Thery JC, Tjan-Heijnen VC, Van den Weyngaert D, Cufer T, Piccart M, Cameron D, Group EO-BC. A European Organisation for Research and Treatment of Cancer randomized, double-blind, placebo-controlled, multicentre phase II trial of anastrozole in combination with gefitinib or placebo in hormone receptor-positive advanced breast cancer (NCT00066378). Eur J Cancer. 2016; 53:144-54. doi: 10.1016/j.ejca.2015.10.012.

12. Finn RS, Crown JP, Lang I, Boer K, Bondarenko IM, Kulyk SO, Ettl J, Patel R, Pinter T, Schmidt M, Shparyk Y, Thummala AR, Voytko NL, et al. The cyclin-dependent kinase $4 / 6$ inhibitor palbociclib in combination with letrozole versus letrozole alone as first-line treatment of 
oestrogen receptor-positive, HER2-negative, advanced breast cancer (PALOMA-1/TRIO-18): a randomised phase 2 study. Lancet Oncol. 2015; 16:25-35. doi: 10.1016/s14702045(14)71159-3.

13. Johnston SR, Kilburn LS, Ellis P, Dodwell D, Cameron D, Hayward L, Im YH, Braybrooke JP, Brunt AM, Cheung KL, Jyothirmayi R, Robinson A, Wardley AM, et al. Fulvestrant plus anastrozole or placebo versus exemestane alone after progression on non-steroidal aromatase inhibitors in postmenopausal patients with hormone-receptor-positive locally advanced or metastatic breast cancer (SoFEA): a composite, multicentre, phase 3 randomised trial. Lancet Oncol. 2013; 14:989-98. doi: 10.1016/S1470-2045(13)70322-X.

14. Baselga J, Campone M, Piccart M, Burris HA 3rd, Rugo HS, Sahmoud T, Noguchi S, Gnant M, Pritchard KI, Lebrun F, Beck JT, Ito Y, Yardley D, et al. Everolimus in postmenopausal hormone-receptor-positive advanced breast cancer. N Engl J Med. 2012; 366:520-9. doi: 10.1056/ NEJMoa1109653.

15. van de Velde CJ, Rea D, Seynaeve C, Putter H, Hasenburg A, Vannetzel JM, Paridaens R, Markopoulos C, Hozumi Y, Hille ET, Kieback DG, Asmar L, Smeets J, et al. Adjuvant tamoxifen and exemestane in early breast cancer (TEAM): a randomised phase 3 trial. Lancet. 2011; 377: 321-31. doi: 10.1016/S0140-6736(10)62312-4.

16. Forbes JF, Cuzick J, Buzdar A, Howell A, Tobias JS, Baum M. Effect of anastrozole and tamoxifen as adjuvant treatment for early-stage breast cancer: 100-month analysis of the ATAC trial. Lancet Oncol. 2008; 9:45-53. doi: 10.1016/s1470-2045(07)70385-6.

17. Kaufmann M, Jonat W, Hilfrich J, Eidtmann $H$, Gademann G, Zuna I, von Minckwitz G. Improved overall survival in postmenopausal women with early breast cancer after anastrozole initiated after treatment with tamoxifen compared with continued tamoxifen: the ARNO 95 Study. J Clin Oncol. 2007; 25:2664-70. doi: 10.1200/ jco.2006.08.8054.

18. Coombes RC, Kilburn LS, Snowdon CF, Paridaens R, Coleman RE, Jones SE, Jassem J, Van de Velde CJ, Delozier T, Alvarez I, Del Mastro L, Ortmann O, Diedrich K, et al. Survival and safety of exemestane versus tamoxifen after 2-3 years' tamoxifen treatment (Intergroup Exemestane Study): a randomised controlled trial. Lancet. 2007; 369:559-70. doi: 10.1016/s0140-6736(07)60200-1.

19. Coates AS, Keshaviah A, Thurlimann B, Mouridsen H, Mauriac L, Forbes JF, Paridaens R, Castiglione-Gertsch M, Gelber RD, Colleoni M, Lang I, Del Mastro L, Smith I, et al. Five years of letrozole compared with tamoxifen as initial adjuvant therapy for postmenopausal women with endocrine-responsive early breast cancer: update of study BIG 1-98. J Clin Oncol. 2007; 25:486-92. doi: 10.1200/ jco.2006.08.8617.

20. Jakesz R, Jonat W, Gnant M, Mittlboeck M, Greil R, Tausch C, Hilfrich J, Kwasny W, Menzel C, Samonigg H,
Seifert M, Gademann G, Kaufmann M, et al. Switching of postmenopausal women with endocrine-responsive early breast cancer to anastrozole after 2 years' adjuvant tamoxifen: combined results of ABCSG trial 8 and ARNO 95 trial. Lancet. 2005; 366:455-62. doi: 10.1016/s01406736(05)67059-6.

21. Coombes RC, Hall E, Gibson LJ, Paridaens R, Jassem J, Delozier T, Jones SE, Alvarez I, Bertelli G, Ortmann O, Coates AS, Bajetta E, Dodwell D, et al. A randomized trial of exemestane after two to three years of tamoxifen therapy in postmenopausal women with primary breast cancer. N Engl J Med. 2004; 350:1081-92. doi: 10.1056/ NEJMoa040331.

22. Baum M, Buzdar A, Cuzick J, Forbes J, Houghton J, Howell A, Sahmoud T. Anastrozole alone or in combination with tamoxifen versus tamoxifen alone for adjuvant treatment of postmenopausal women with early-stage breast cancer: results of the ATAC (Arimidex, Tamoxifen Alone or in Combination) trial efficacy and safety update analyses. Cancer. 2003; 98:1802-10. doi: 10.1002/cncr.11745.

23. Buzdar AU, Jonat W, Howell A, Jones SE, Blomqvist CP, Vogel CL, Eiermann W, Wolter JM, Steinberg M, Webster A, Lee D. Anastrozole versus megestrol acetate in the treatment of postmenopausal women with advanced breast carcinoma: results of a survival update based on a combined analysis of data from two mature phase III trials. Arimidex Study Group. Cancer. 1998; 83:1142-52.

24. Goss PE, Ingle JN, Pritchard KI, Ellis MJ, Sledge GW, Budd GT, Rabaglio M, Ansari RH, Johnson DB, Tozer R, D'Souza DP, Chalchal H, Spadafora S, et al. Exemestane versus anastrozole in postmenopausal women with early breast cancer: NCIC CTG MA.27-a randomized controlled phase III trial. J Clin Oncol. 2013; 31:1398-404. doi: 10.1200/JCO.2012.44.7805.

25. Iwata H, Masuda N, Ohno S, Rai Y, Sato Y, Ohsumi S, Hashigaki S, Nishizawa Y, Hiraoka M, Morimoto T, Sasano H, Saeki T, Noguchi S. A randomized, double-blind, controlled study of exemestane versus anastrozole for the first-line treatment of postmenopausal Japanese women with hormone-receptor-positive advanced breast cancer. Breast Cancer Res Treat. 2013; 139:441-51. doi: 10.1007/ s10549-013-2573-3.

26. Aihara T, Takatsuka Y, Ohsumi S, Aogi K, Hozumi Y, Imoto S, Mukai H, Iwata $\mathrm{H}$, Watanabe $\mathrm{T}$, Shimizu $\mathrm{C}$, Nakagami K, Tamura M, Ito T, et al. Phase III randomized adjuvant study of tamoxifen alone versus sequential tamoxifen and anastrozole in Japanese postmenopausal women with hormone-responsive breast cancer: N-SAS BC03 study. Breast Cancer Res Treat. 2010; 121:379-87. doi: 10.1007/s10549-010-0888-x.

27. Moher D, Liberati A, Tetzlaff J, Altman DG, Group P. Preferred reporting items for systematic reviews and metaanalyses: the PRISMA statement. PLoS Med. 2009; 6: e1000097. doi: 10.1371/journal.pmed.1000097. 
28. Altman DG, Bland JM. Interaction revisited: the difference between two estimates. BMJ. 2003; 326: 219.

29. Kyvernitakis I, Ziller V, Hars O, Bauer M, Kalder M, Hadji P. Prevalence of menopausal symptoms and their influence on adherence in women with breast cancer. Climacteric. 2014; 17:252-9. doi: 10.3109/13697137.2013.819327.

30. Rosenberg SM, Stanton AL, Petrie KJ, Partridge AH. Symptoms and Symptom Attribution Among Women on Endocrine Therapy for Breast Cancer. Oncologist. 2015; 20: 598-604. doi: 10.1634/theoncologist.2015-0007.

31. Gupta P, Sturdee DW, Palin SL, Majumder K, Fear R, Marshall T, Paterson I. Menopausal symptoms in women treated for breast cancer: the prevalence and severity of symptoms and their perceived effects on quality of life. Climacteric. 2006; 9:49-58. doi: 10.1080/13697130500487224.

32. Han NR, Kim HY, Yang WM, Jeong HJ, Kim HM. Glutamic acid ameliorates estrogen deficiency-induced menopausallike symptoms in ovariectomized mice. Nutr Res. 2015; 35: 774-83. doi: 10.1016/j.nutres.2015.06.006.

33. Abdi F, Mobedi H, Roozbeh N. Hops for Menopausal Vasomotor Symptoms: Mechanisms of Action. J Menopausal Med. 2016; 22:62-4. doi: 10.6118/jmm.2016.22.2.62.

34. Luptakova L, Sivtakova D, Cernanova V, Cvicelova M. Menopausal complaints in Slovak midlife women and the impact of CYP1B1 polymorphism on their incidence. Anthropol Anz. 2012; 69:399-415.

35. Memon ZA, Qurrat ul A, Khan R, Raza N, Noor T. Clinical Presentation and Frequency of Risk Factors in Patients with Breast Carcinoma in Pakistan. Asian Pac J Cancer Prev. 2015; 16:7467-72.

36. Inwald EC, Koller M, Klinkhammer-Schalke M, Zeman F, Hofstadter F, Lindberg P, Gerstenhauer M, Schuler S, Treeck O, Ortmann O. Adjuvant endocrine therapy in pre- versus postmenopausal patients with steroid hormone receptor-positive breast cancer: results from a large population-based cohort of a cancer registry. J Cancer Res Clin Oncol. 2015; 141:2229-40. doi: 10.1007/s00432-0152025-z.

37. Chien AJ, Duralde E, Hwang R, Tsung $\mathrm{K}$, Kao CN, Rugo HS, Melisko ME, Esserman LJ, Munster PN, Cedars M, Kerlikowske K, McCulloch CE, Rosen MP. Association of tamoxifen use and ovarian function in patients with invasive or pre-invasive breast cancer. Breast Cancer Res Treat. 2015; 153:173-81. doi: 10.1007/s10549015-3511-3.

38. Mortimer JE, Flatt SW, Parker BA, Gold EB, Wasserman L, Natarajan L, Pierce JP, Group WS. Tamoxifen, hot flashes and recurrence in breast cancer. Breast Cancer Res Treat. 2008; 108:421-6. doi: 10.1007/s10549-007-9612-x.

39. Chen Y, Dorjgochoo T, Bao PP, Zheng Y, Cai H, Lu W, Shu XO. Menopausal symptoms among breast cancer patients: a potential indicator of favorable prognosis. PLoS One. 2013; 8:e75926. doi: 10.1371/journal.pone.0075926.
40. Eden J. ENDOCRINE DILEMMA: Managing menopausal symptoms after breast cancer. Eur J Endocrinol. 2016; 174: R71-7. doi: 10.1530/eje-15-0814.

41. Durna EM, Wren BG, Heller GZ, Leader LR, Sjoblorn P, Eden JA. Hormone replacement therapy after a diagnosis of breast cancer: cancer recurrence and mortality. Medical Journal of Australia. 2002; 177:347-51.

42. Holmberg L, Iversen OE, Rudenstam CM, Hammar M, Kumpulainen E, Jaskiewicz J, Jassem J, Dobaczewska D, Fjosne HE, Peralta O, Arriagada R, Holmqvist M, Maenpa J. Increased risk of recurrence after hormone replacement therapy in breast cancer survivors. Journal of the National Cancer Institute. 2008; 100:475-82. doi: 10.1093/jnci/djn058.

43. Sedgwick P. Meta-analyses: what is heterogeneity? BMJ. 2015; 350:h1435. doi: 10.1136/bmj.h1435.

44. Zhang $\mathrm{Z}, \mathrm{Xu} \mathrm{X}, \mathrm{Ni} \mathrm{H}$. Small studies may overestimate the effect sizes in critical care meta-analyses: a metaepidemiological study. Crit Care. 2013; 17:R2. doi: 10.1186/cc11919.

45. Cramer H, Lauche R, Langhorst J, Dobos G. Effectiveness of yoga for menopausal symptoms: a systematic review and meta-analysis of randomized controlled trials. Evid Based Complement Alternat Med. 2012; 2012:863905. doi: $10.1155 / 2012 / 863905$.

46. Franco $\mathrm{OH}$, Chowdhury $\mathrm{R}$, Troup $\mathrm{J}$, Voortman $\mathrm{T}$, Kunutsor S, Kavousi M, Oliver-Williams C, Muka T. Use of Plant-Based Therapies and Menopausal Symptoms: A Systematic Review and Meta-analysis. JAMA. 2016; 315 : 2554-63. doi: 10.1001/jama.2016.8012.

47. Jadad AR, Moore RA, Carroll D, Jenkinson C, Reynolds DJ, Gavaghan DJ, McQuay HJ. Assessing the quality of reports of randomized clinical trials: is blinding necessary? Control Clin Trials. 1996; 17:1-12.

48. Sweeting MJ, Sutton AJ, Lambert PC. What to add to nothing? Use and avoidance of continuity corrections in meta-analysis of sparse data. Stat Med. 2004; 23:1351-75. doi: 10.1002/sim. 1761 .

49. Zintzaras E, Ioannidis JP. Heterogeneity testing in metaanalysis of genome searches. Genet Epidemiol. 2005; 28: 123-37. doi: 10.1002/gepi.20048.

50. Higgins JP, Thompson SG, Deeks JJ, Altman DG. Measuring inconsistency in meta-analyses. BMJ. 2003; 327: 557-60. doi: 10.1136/bmj.327.7414.557.

51. Begg CB, Mazumdar M. Operating characteristics of a rank correlation test for publication bias. Biometrics. 1994; 50: 1088-101.

52. Egger M, Davey Smith G, Schneider M, Minder C. Bias in meta-analysis detected by a simple, graphical test. BMJ. 1997; 315:629-34. 